\title{
$\begin{array}{ll}\text { Research Square } & \text { Preprints are preliminary reports that have not undergone peer review. } \\ \text { They should not be considered conclusive, used to inform clinical practice, }\end{array}$ or referenced by the media as validated information. \\ An Empirical Analysis of Policy Barriers Related to Trade Costs for Exporters
}

Shabana Noureen ( $\nabla$ shabana-noureen@s3h.nust.edu.pk)

National University of Sciences and Technology, Islamabad, Pakistan https://orcid.org/0000-00027699-6647

\section{Zafar Mahmood}

National University of Sciences and Technology, Islamabad, Pakistan.

\section{Research}

Keywords: Tariff Barriers, Non-Tariff Barriers, Policy Barriers, Trade Costs, Trade Policies, Trading Partners

Posted Date: August 13th, 2020

DOl: https://doi.org/10.21203/rs.3.rs-55415/v2

License: (1) This work is licensed under a Creative Commons Attribution 4.0 International License. Read Full License 
The authors have withdrawn this preprint from Research Square 